\title{
Reconfigurable Tooling by Using a Reconfigurable Material
}

\author{
Jorge Cortés, Ignacio Varela-Jiménez and Miguel Bueno-Vives \\ Tecnológico de Monterrey, Campus Monterrey \\ México
}

\section{Introduction}

Changes in manufacturing environment are characterized by aggressive competition on a global scale and rapid changes in process technology; these require creation of production systems easily upgradable by themselves and into which new technologies and new functions can be readily integrated (Mehrabi et al, 2000). In USA; industry, government and other institutions have identified materials and manufacturing trends for 2020 (Vision 2020 Chemical Industry of The Future, 2003 \& National Research Council, 1998). The materials Technology Vision committee, in the publication of "Technology Vision 2020The U.S. Chemical Industry" has identified a number of broad goals, which are enclosed in five main areas:

- New materials

- Materials characterization

- Materials modeling and prediction

- Additives

- Recycling

An important point in this vision is the development of smart materials, which have properties of self-repair, actuate and transduce. Polymers, metals, ceramics and fluids with these special characteristics belong to this class of materials and are already used in a great diversity of applications (Vision 2020 Chemical Industry of The Future, 2003).

In the other hand, the Visionary Manufacturing Challenges (National Research Council, 1998), published by the US National Academy of Sciences, presented six Grand Challenges:

- Integration of Human and Technical Resources

- Concurrent Manufacturing

- Innovative Processes

- Conversion of Information to Knowledge

- Environmental Compatibility

- Reconfigurable Enterprise

To reach these challenges, innovative processes to design and to manufacture new materials and components along with adaptable, integrated equipment, processes, and systems that 
can be readily reconfigured for a wide range of customer requirements or products, features, and services are needed (National Research Council, 1998).

The field of smart materials and structures is emerging rapidly with technological innovations appearing in engineering materials, sensors, actuators and image processing (Kallio et al, 2003). One of the smart materials is Nickel - Titanium alloy (NiTi) that possess an interesting property by which the metal 'remembers' its original size or shape and reverts to it at a characteristic transformation temperature (Srinivasan \& McFarland, 2001).

Next manufacturing system generation requires of reconfigurable systems which go beyond the objective of mass, lean and flexible manufacturing systems. Because of the manufacturing trends towards a customer focused production. A reconfigurable manufacturing system is designed in order to rapid adjustment of production capacity and functionality, in response to new circumstances, by rearrangement or change of its components (Mehrabi et al, 2000). As can be seen in Fig. 1, there are many aspects of reconfiguration, such as, configuration of the product system, reconfiguration of the factory communication software, configuration of new machine controllers, building blocks and configuration of modular machines, modular processes, and modular tooling. So that, the development and implementation of key interrelated technologies to achieve the goals of reconfigurable manufacturing systems are needed.

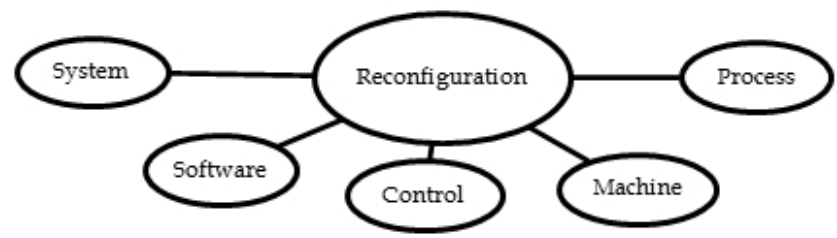

Fig. 1. Aspects of reconfiguration (Mehrabi et al, 2000).

Of relevant importance are the control, monitoring and sensing of reconfigurable manufacturing systems. By noting that the system configuration changes, the parameters of the production machines and some other physical parameters will change accordingly. The controller and process monitoring systems should have the ability to reconfigure and adapt themselves to these new conditions (Mehrabi et al, 2000).

\subsection{Research justification}

The use of NiTi requires proper characterization according to the environment surrounding the material when it is applied in some device; due to this requirement, a constitutive model is needed in order to relate the microstructure and thermo-mechanical behavior of the material.

In the manufacture industry, a variable shape die has always been an attractive idea to reduce design time and costs, since it allows as many designs to be rapidly manufactured at nearly free cost, using one tool for several shapes (Li et al, 2008).

The use of NiTi as an actuator in manufacturing systems is an opportunity area, allowing that several products can be formed by the same tool; this way, NiTi will help to evolve the traditional manufacturing industry. 


\subsection{Research aim}

To develop a reconfigurable manufacture system for sheet metal/plastic forming controlled by NiTi actuators and to formulate a constitutive model of its thermo- mechanical behavior.

\section{Constitutive model}

$\mathrm{NiTi}$ is a smart material with properties such as shape memory effect (SME) and superelasticity (Chang \& Wu, 2007). SME involves the recovery of residual inelastic deformation by raising the temperature of the material above a transition temperature, whereas in superelasticity, large amounts of deformation (up to 10\%) can be recovered by removing the applied loads (Azadi et al, 2007).

The microscopic mechanisms involved in SME are strongly correlated to the transformation between the austenite parent phase at high temperatures and the martensite at low temperatures (Lahoz \& Puértolas, 2004). It is a reversible, displacive, diffusionless, solidsolid phase transformation from a highly ordered austenite to a less ordered martensite structure (McNaney et al, 2003). Austenite has a body centered cubic lattice while martensite is monoclinic. When NiTi with martensitic structure is heated, it begins to change into the austenitic phase. This phenomenon starts at a temperature denoted by $A_{s}$, and is complete at a temperature denoted by $A_{f}$. When austenitic NiTi is cooled, it begins to return to its martensitic structure at a temperature denoted by $M_{s}$, and the process is complete at a temperature denoted by $M_{f}$ (Nemat-Nasser et al, 2006). Because austenite is usually higher in strength than martensite, a large amount of useful work accompanies the shape change. Austenite exhibits higher stiffness than martensite (De Castro et al, 2007).

When NiTi is stressed at a temperature close to $A_{f}$, it can display superelastic behavior. This stems from the stress-induced martensite formation, since stress can produce the martensitic phase at a temperature higher than $M_{s}$, where macroscopic deformation is accommodated by the formation of martensite. When the applied stress is released, the martensitic phase transforms back into the austenitic phase and the specimen returns back to its original shape (Nemat-Nasser et al, 2006). The stress-induced austenite-martensite transformation is effected by the formation of martensitic structures which correspond to system energy minimizers (McNaney et al, 2003) as result of the need of the crystal lattice structure to accommodate to the minimum energy state for a given temperature (Ryhänen, 1999).

Shaw explains in more detail martensite behavior, affirming that due to its low degree of symmetry, the martensite exists either as a randomly twinned structure (low temperature, low stress state) or a stress-induced detwinned structure that can accommodate relatively large, reversible strains. Fig. 2 shows the thermomechanical response of a wire specimen. The specimen is first subjected to a load/unload cycle at low temperature, leaving an apparent permanent strain. The material starts in a twinned martensite (TM) state and becomes detwinned (DM) upon loading. The specimen is then subjected to a temperature increase while holding the load. The SME is seen as the strain is recovered and the material transforms to austenite (A). The temperature is then held at high value and the specimen is again subjected to a load/unload cycle. In this case the material shows superelasticity and transforms from austenite to detwinned martensite during loading and then back to austenite during unloading (Shaw, 2002). 


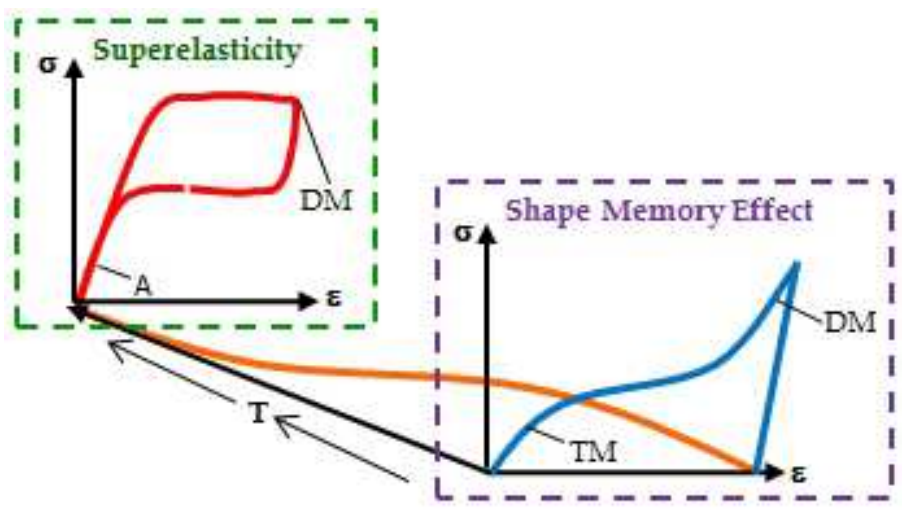

Fig. 2. Thermomechanical cycle of NiTi (Shaw, 2002)

It is considered that composition (Nemat-Nasser et al, 2006) and heat treatments have effect on the temperature at which material exhibits SME, called transformation temperatures (TTR) which are the prerequisite for the material to exhibit the SME and are one of the key parameters for SME based actuation, they also define the proper application for a certain NiTi composition alloy (Malukhin \& Ehmann, 2006).

Establishment of a constitutive equation for phase transformation in NiTi requires considering the Stress-Strain-Temperature behavior and the phase transformations shown in Fig. 2, from which is observed that volume fraction of each microstructure depends of the strain and temperature conditions; it also has influence on the mechanical behavior of the material.

The possible phase transformations that can occur on NiTi are shown in Fig. 3, strain induces detwinned martensite while temperature increase induces austenite. As shown in Fig. 2, at low temperature and low stress, transformation of twinned martensite into detwinned martensite is started, and continues its plastic strain and then stress is released. When temperature is increased detwinned martensite transforms into austenite. If high temperature is kept and strain is applied superelasticity occurs and transformation of austenite into detwinned martensite is started, it finishes when stress is released and then microstructure transforms back into austenite.

According to Fig. 3, phase transformations on NiTi are:

1. Twinned martensite to Detwinned martensite (Strain induced)

2. Detwinned martensite to Austenite (Temperature increase induced)

3. Austenite to Detwinned Martensite (Strain induced)

4. Twinned martensite to Austenite (Temperature increase induced)

5. Austenite to Twinned Martensite (Temperature decrease induced)

Up to day, several studies have been made about NiTi, but there is a lack in the development of numerical analysis of the phenomenology of the material since its application requires a proper characterization; a constitutive model is needed in order to relate microstructure and thermo-mechanical behavior of NiTi. A similar model was developed by Cortes (Cortes et al, 1992) for determining the flow stress of aggregates with phase transformation induced by strain, stress or temperature and demonstrated its use for stainless steels. This model has also 
been applied on shape memory polymers (Varela et al, 2010) and it has been extended for modeling the displacement on electroactive polymers (Guzman et al, 2009) through a phase transformation approach, induced by some external stimulus. The model is based on an energy criterion which defines the energy consumed to deform the phases in the system as being equivalent to energy consumed to deform the aggregate and it is able to predict the flow stress behavior of the material. In order to apply Cortes' constitutive model on SMAs, experiments have to be carried out; the austenite, twinned martensite and detwinned martensite are considered as the aggregates and the microstructural transition between them becomes the basis of the constitutive model; this way, the constitutive expression will result in terms of the mechanical properties of each phase and its volume fraction.

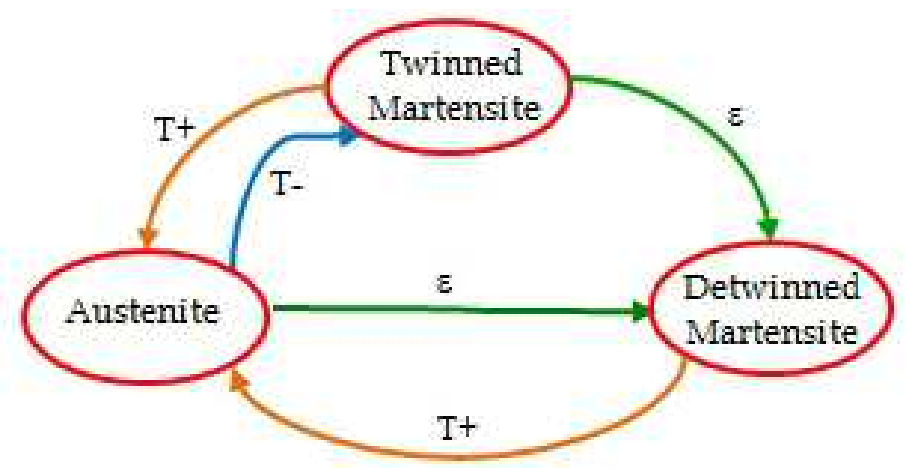

Fig. 3. Phase Transformations on NiTi and their induction stimulus.

\subsection{Constitutive model of flow stress}

In the case of the present aggregate composed of austenite and martensite, based on Cortes model (Cortes et al, 1992), $V_{f}$ of each structure or aggregate are defined as:

$$
V_{f a=} \frac{V_{a}}{V_{t}} \quad V_{f t m}=\frac{V_{t m}}{V_{t}} \quad V_{f d m}=\frac{V_{d m}}{V_{t}}
$$

where subscripts $a, t m$ and $d m$ indicate austenite, twinned martensite and detwinned martensite, respectively . Cortes constitutive model of flow stress for multi phases aggregate (Cortes et al, 1992) applied on NiTi is

$$
\sigma_{N i T i}=V_{f a} \cdot \sigma_{a}+V_{f t m} \cdot \sigma_{t m}+V_{f d m} \cdot \sigma_{d m}
$$

where $\sigma_{\mathrm{NiTi}}$ is stress of $\mathrm{NiTi}$ and $\sigma_{a}, \sigma_{t m}$ and $\sigma_{d m}$ are stress of each structure.

\subsection{Kinetics of strain/temperature induced twinned martensite-detwinned martensite- austenite phase transformation}

Based on the thermomechanical behavior of Fig. 2 and the phase transformations shown in Fig. 3, volume fraction of the microstructures varies by:

$$
V_{f a}+V_{f t m}+V_{f d m}=1
$$




$$
\begin{gathered}
V_{f a}=\left(1-V_{f a-d m}\right) \cdot V_{f a_{0}}+V_{f t m-a} \cdot V_{f t m_{0}}+V_{f d m-a} \cdot V_{f d m_{0}} \\
V_{f d m}=\left(1-V_{f d m-a}\right) \cdot V_{f d m_{0}}+V_{f t m-d m} \cdot V_{f t m_{0}}+V_{f a-d m} \cdot V_{f a_{0}}
\end{gathered}
$$

where subscripts 0 indicate the initial valume of each volume fraction.

For strain induced detwinned martensite phase transformation:

$$
V_{f d m}=\left[1+\left(\frac{\varepsilon}{\varepsilon_{c}}\right)^{-B}\right]^{-1}
$$

For temperature induced austenite phase transformation:

$$
V_{f a}=\left[1+\left(\frac{T}{T_{c}}\right)^{-B}\right]^{-1}
$$

where $B$ is a fitting constant; while $\varepsilon_{c}$ and $T_{c}$ represent the values of strain and temperature, respectively at which $50 \%$ of the phase transformation is occurred. Experimental work is required for determining these values for each phase transformation. Substituting (6) and (7) in (4) and (5):

$$
\begin{aligned}
& V_{f_{a}}=\left\{1-\left[1+\left(\frac{\varepsilon}{\varepsilon_{C 3}}\right)^{-B_{3}}\right]^{-1}\right\} \cdot V_{f_{a_{0}}}+\left[1+\left(\frac{T}{T_{C 4}}\right)^{-B_{4}}\right]^{-1} \cdot V_{f_{t m_{0}}}+\left[1+\left(\frac{T}{T_{C 2}}\right)^{-B_{2}}\right]^{-1} \cdot V_{f d m_{0}} \\
& V_{f_{d m}}=\left\{1-\left[1+\left(\frac{T}{T_{C 2}}\right)^{-B_{2}}\right]^{-1}\right\} \cdot V_{f_{t m_{0}}}+\left[1+\left(\frac{\varepsilon}{\varepsilon_{C 1}}\right)^{-B_{1}}\right]^{-1} \cdot V_{f_{t m_{0}}}+\left[1+\left(\frac{\varepsilon}{\varepsilon_{C 3}}\right)^{-B_{3}}\right]^{-1} \cdot V_{f a_{0}}
\end{aligned}
$$

where subscripts $1,2,3$ and 4 represent the $B, T_{c}$ or $\varepsilon_{c}$ value corresponding to that phase transformation.

\subsection{Stress of microstructures}

Since NiTi contains a heterogeneous microstructure under given conditions, an incremental change test to determine hardening parameters in a given structure has to be carried out. Based in Cortes work (Cortes et al, 1992) flow stress of austenite, twinned martensite and detwinned martensite is determined under isothermal conditions, by prestraining NiTi wires at a temperature at which only one microstructure exists, and then the specimens were individually deformed at a predefined temperature. The yielding point in reloading is registered as the flow stress at that temperature and those strain conditions. From this experiment equations for estimating $\sigma_{a}, \sigma_{t m}$ and $\sigma_{d m}$ are determined. These should be of the form:

$$
\sigma_{a}=K_{a} \cdot \varepsilon^{N_{a}}
$$




$$
\begin{gathered}
\sigma_{t m}=K_{t m} \cdot \varepsilon^{N_{t m}} \\
\sigma_{d m}=K_{d m} \cdot \varepsilon^{N_{d m}}
\end{gathered}
$$

where $K$ and $N$ represent material constants which are determined experimentally.

By substituting equations (3) and (8)-(12) into equation (1) stress on NiTi can be described relating thermomechanical behavior with microstructure.

\section{Reconfigurable die}

Conventional type of mold fabrication involves time and money investment to achieve design of a die; the concept about forming a die of variable shape has always been attractive as a means of rapid iterations and almost cost free ( $\mathrm{Li}, 2008)$. Thus, multi forming methods have been developed in order to achieve reconfigurability of the process.

\subsection{Multi point forming (MPF)}

This method has been used to replace solid dies with three-dimensional surfaces. The main key of the MPF is the two matrices of punches allowing that create a three-dimensional surface which forms according to the shape of the design; this way the surface can be approximated to a continuous die, as shown in Fig. 4 (Zhong-Yi, 2002).

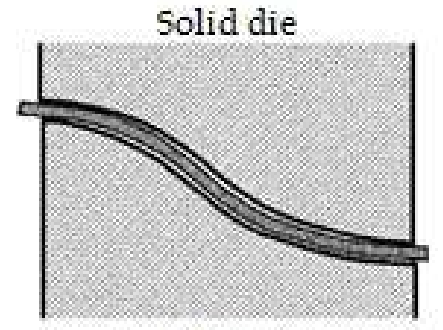

(a)

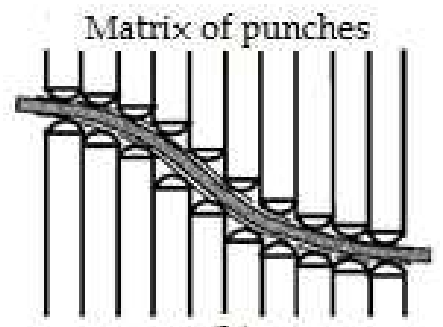

(b)

Fig. 4. (a) Conventional die forming; (b) Multi-point forming (Zhong, 2002).

MPF is based on controlling the elements and punches, hence, a matrix on punches can be shaped as required ( $\mathrm{Li}, 2002)$. Fig. 5. illustrates the parameters related to the reconfigurable process: design and manufacture of the pin heads; since its shape, size and length play an important role in the arrangement of the closed matrix (Walczyk, 1998).

Design of a tool based on multi-point technique has many considerations since it involves several variables and many issues and problems use to occur such as dimpling, buckling and non linear deformation of the material; due to this issues four main designs have been researched with different punches types $(\mathrm{Li}, 2002)$.

- Multi-point full die

- Multi-point half die

- Multi-point full press

- Multi-point half press 


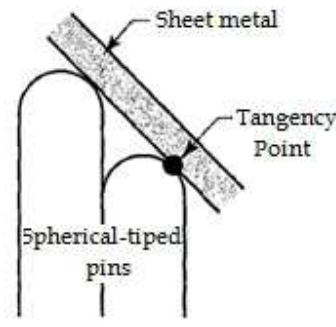

(a)

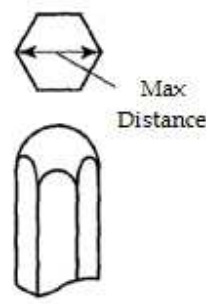

(b)

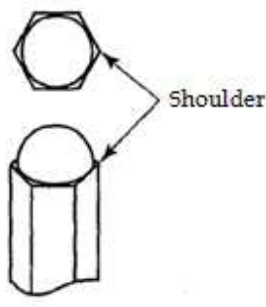

(c)

Fig. 5. Spherical and Hexagonal pin head designs (Li, 2002).

The arrangement of each design is described and shown in Table 1 and Fig. 6, respectively.

\begin{tabular}{|c|c|c|c|}
\hline Type of Punch & Adjustment & Required Force & Drawing/Mark \\
\hline Fixed & $\begin{array}{c}\text { Before } \\
\text { Forming }\end{array}$ & Small \\
\hline Passive & $\begin{array}{c}\text { While } \\
\text { Forming }\end{array}$ & None \\
\hline Active & $\begin{array}{c}\text { Free } \\
\text { Movement }\end{array}$ & Large & \\
\hline
\end{tabular}

Table 1. Different types of MPF.

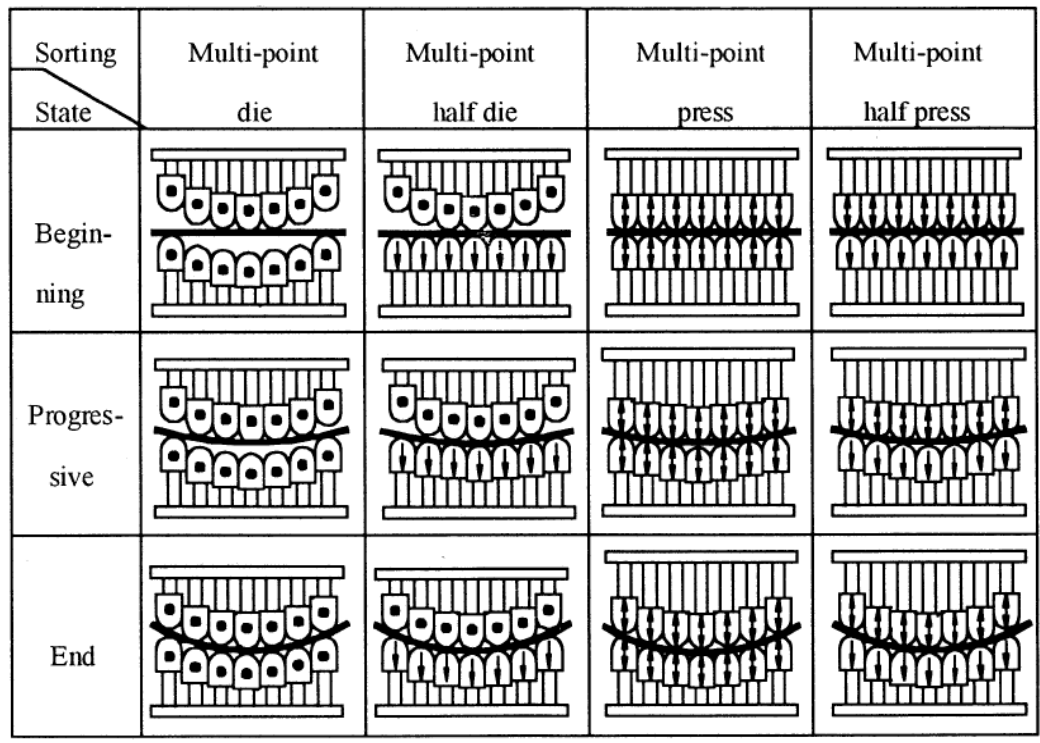

Fig. 6. Different types of Multi-point forming and the interaction with the process (Walczyk, 1998). 


\subsubsection{Multi-point sandwich forming (MPSF)}

MPSF is an accessible method to manufacture components in small batches. Fig. 7 represents the MPSF method which uses an interpolator material to assure the surface quality of the metal sheet, this last also depends of the tool elements and the position between the pins (Zhang, 2006).

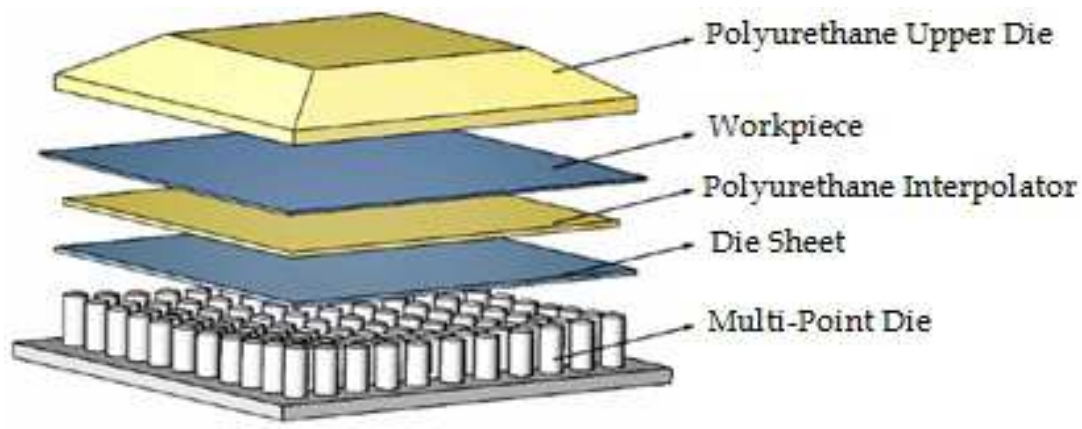

Fig. 7. Schematic Components for MPSF (Zhang, 2006).

\subsubsection{Digitized die forming (DDF)}

With DDF, forming procedures and integration between parameters such as deformation path, sectional forming; punches and control loop are being developed in order to avoid forming defects. The process is shown in Fig. 8 (Li, 2007).

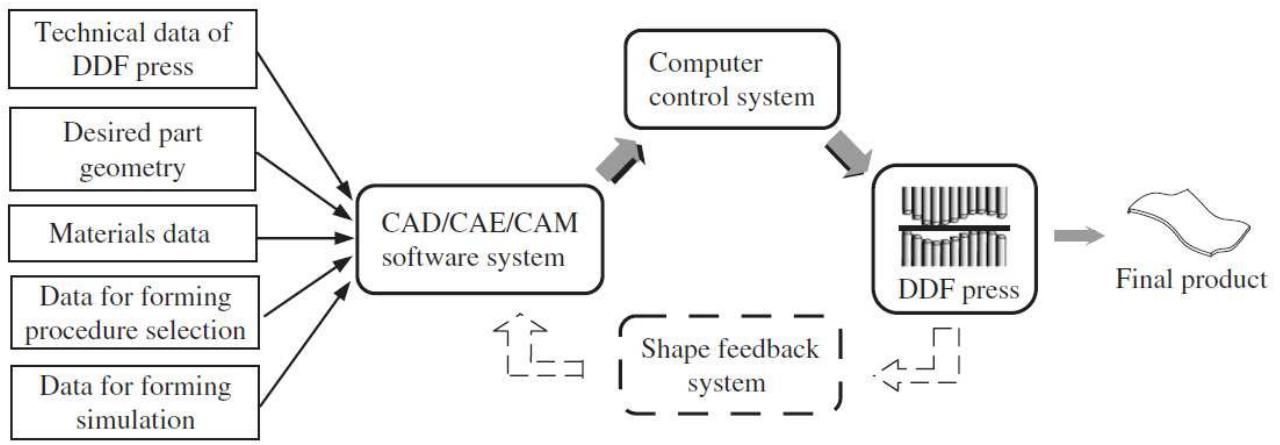

Fig. 8. Schematic of DDF integration system (Li, 2007).

\subsection{Active multi point forming parameters}

\subsubsection{Pin head}

A pin head must be strong enough to support the mechanical and thermal loads of the material to manufacture avoiding the problems in the final piece such as bending, buckling and dimpling (Walczyk, 1998). In addition to normal or vertical load, the pin will be subjected to lateral load depending the height and of the adjacent pins on the shape; this variable is a key factor on the pin head design (Schwarz, 2002), as shown in Fig. 9. 
Uniformity in the pin heads and elements make the design easy to fabricate and assembly in the arrangement of the matrix, a comparison of different geometries evaluating the crosssectional area shape is shown in Table 2 (Schwarz, 2002).

\begin{tabular}{|l|c|c|c|c|}
\hline \multicolumn{1}{|c|}{ Pin Cross-Section Shape } & Equilateral Triangle & Square & Hexagonal & Circle \\
\hline Number of Sides & 3 & 4 & 6 & 6 \\
\hline No. Isolated straight load paths & 0 & 2 & 3 & 0 \\
\hline
\end{tabular}

Table 2. Comparison of Cross-Sectional Geometry.

Also the structure and the size of the pins affect the quality of the piece and it is recommended the use of square shape elements, as shown in Fig. 10, in dense packed arrangements of matrices (Schwarz, 2002).

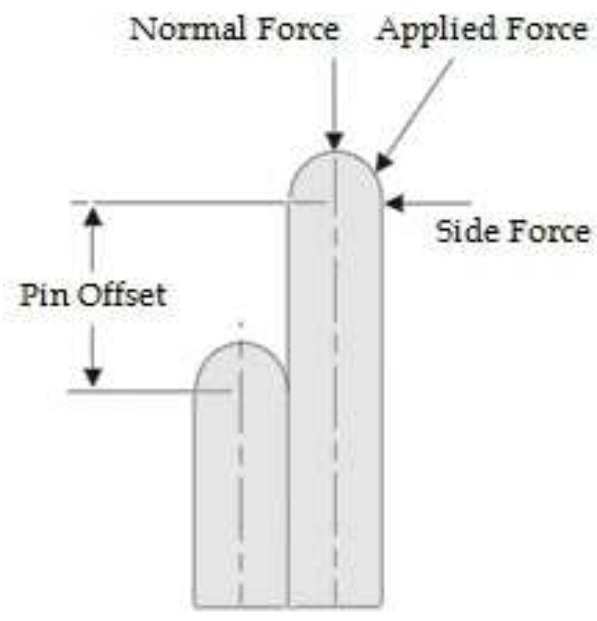

Fig. 9. Pin head forces interaction and offset.

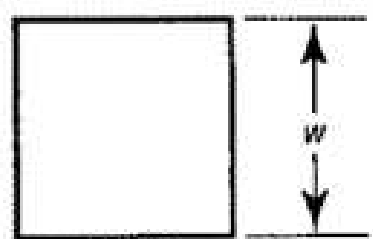

(a) Solid

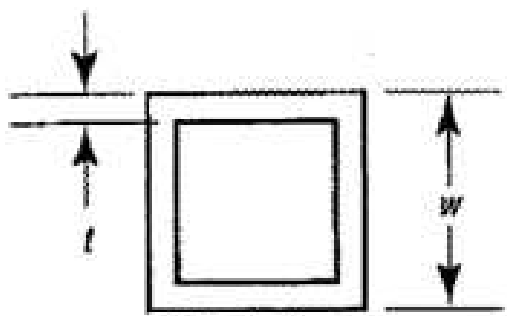

(b) Tubular

Fig. 10. Square design a) Solid and b) Tubular (Schwarz, 2002).

The use use of tubular elements is considered if the weight of the die has to be reduced, however it is not always is the best approach considering the scale and size of pins and the forces of the process (Schwarz, 2002). 


\subsubsection{Actuators}

Each design of a shape has different means of independently moving pins in a large matrix arrangement (Walczyk, 2000). Automation of pin setting was not realized until in 1969 Nakajima positioned a matrix of pins controlled by a vibration mechanism mounted to a three-axis servomechanism (Nakajima, 1986). It is shown in Fig. 11.

Researches from different groups such as, the Massachusetts Institute of Technology (MIT) developed a Sequential Set-up Concept, the Rensselaer Polytechnic Institute build up a Hydraulic Actuation Concept and the Northrop Grumman Group Corporation created a Shaft-driven Lead screw Concept (Walczyk, 2000)

\section{Sequential Set-up (SSU) by MIT}

Each hollow pin has a threaded nut passed from its base. The pin moves up and down as the lead screw rotates, and the next pin prevent the rotation movement; the design eliminates the matrix external clamping force to position the pin heads.

\section{Hydraulically Actuation (HA) by Renselaer Polytechnic}

Individual elements are essentially hydraulic actuators, controlled by an in-line servo valve. The hydraulic pressure makes the element rise from the initial position maintaining the height until the pressure is released.

\section{Shaft Driven Lead screw (SDL) by Northrop Group}

This method depending on the need of the process needs a single or dual electric motor (one each on opposing sides of the die) mounted externally to drive worms mounted on cross shafts; the worm gear is connected to each pin's lead screw.

Table 3 shows a comparison between these designs.

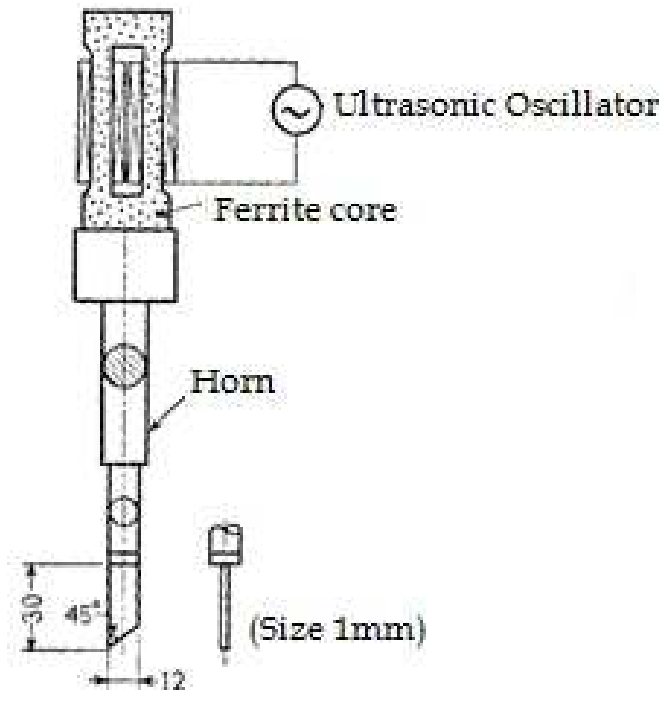

Fig. 11. Nakajima servomechanism (Nakajima, 1986). 


\begin{tabular}{|c|c|c|c|}
\hline Characteristic & SSU & HA & SDL \\
\hline Matrix of Pins & 42x64 (28.6mm pin) & $48 \times 72$ (25.4mm pin) & $42 \times 64$ (28.6mm pin) \\
\hline $\begin{array}{l}\text { Number of } \\
\text { Actuators }\end{array}$ & $\begin{array}{l}19 \text { (16 drive motors, } X, Y \\
\text { and } Z \text { axes) }\end{array}$ & 1 (Hydraulic pump) & $\begin{array}{l}42 \text { (drive motor per } \\
\text { row) }\end{array}$ \\
\hline $\begin{array}{l}\text { Number of } \\
\text { position } \\
\text { control devices }\end{array}$ & 0 & 3456 (servo valve per pin) & 2688 (clutch per pin) \\
\hline $\begin{array}{l}\text { Number of } \\
\text { sensors }\end{array}$ & 19 & 1 & $\begin{array}{l}42 \text { (encoders per } \\
\text { motor) }\end{array}$ \\
\hline $\begin{array}{l}\text { Potential } \\
\text { mayor of } \\
\text { positioning } \\
\text { error }\end{array}$ & Backlash in lead screw & $\begin{array}{l}\text { Insufficient platen } \\
\text { stiffness }\end{array}$ & Rotational compliance \\
\hline Setting mode & Serial & Parallel & Parallel \\
\hline $\begin{array}{l}\text { Potential } \\
\text { control mode } \\
\text { error }\end{array}$ & $\begin{array}{l}\text { Lead screw is } \\
\text { continuously engaged }\end{array}$ & $\begin{array}{l}\text { Moving pins are in } \\
\text { contact with platen }\end{array}$ & Clutch does not slip \\
\hline $\begin{array}{l}\text { Concept } \\
\text { Design }\end{array}$ & Drive motor & Fluid & $\begin{array}{l}\text { Leadscrew } \\
\text { Whashers } \\
\text { bearing }\end{array}$ \\
\hline
\end{tabular}

Table 3. Comparison of Actuation schemes for Dies (Walczyk, 2000).

As shown in table 3; the use of common actuators have problems to form a continuous even surface, due to the size of the actuators the element diameter has to be at least $25.4 \mathrm{~mm}$, also the actuators and the relationship in a potential control mode error by mechanical characteristics such as fatigue and cycles limit the use of the die in order to make different shapes (Walczyk, 2000).

\subsubsection{Matrix arrangement}

Design and manufacturability of the pins impact the position and design of the matrix due to the number of sides on the cross-sectional shape geometry. Fig. 12 shows the key factor of densely packed pin heads in a matrix; allowing management of the load and maintaining a smoother surface when subjected to loads. The contact elements have to be maximized while the gaps between elements need to be minimized (Schwarz, 2002). 


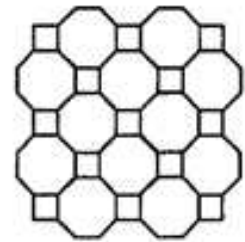

Octagonal and square

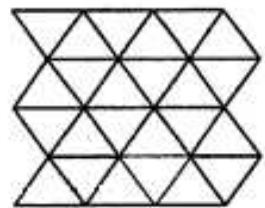

Triangular

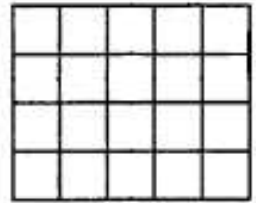

Square

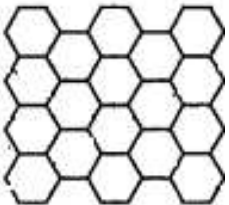

Hexagonal

Fig. 12. Various Cross-Sectional shapes for die pins (Schwarz, 2002).

Shown in Fig. 12 is a discrete digitalized arrangement to a continuous surface with multi point forming die technology. It is important to have as many pins as possible since a poor transition surface may result in delicate wrinkling defect and possible cracking of the work piece (Peng, 2006).
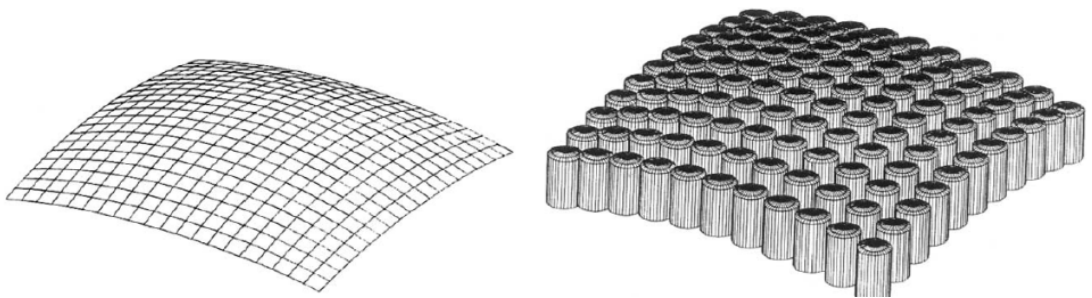

Fig. 13. Discrete approximation to a continuous surface square position (Rao, 2002).

\subsubsection{Control and software}

The desired part to be manufactured generating a controlling data in height of the piece is sent to a control system to perform the DDF (Li, 2007). Fig. 15. shows the different technologies merging to make the software design and control available to a reconfigurable design. An open loop control system and electronic on a single pin element, are used to evaluate a simpler circuit and timed software to excite the actuator (Walczyk \& Hardt, 1998), as shown in Fig. 14.

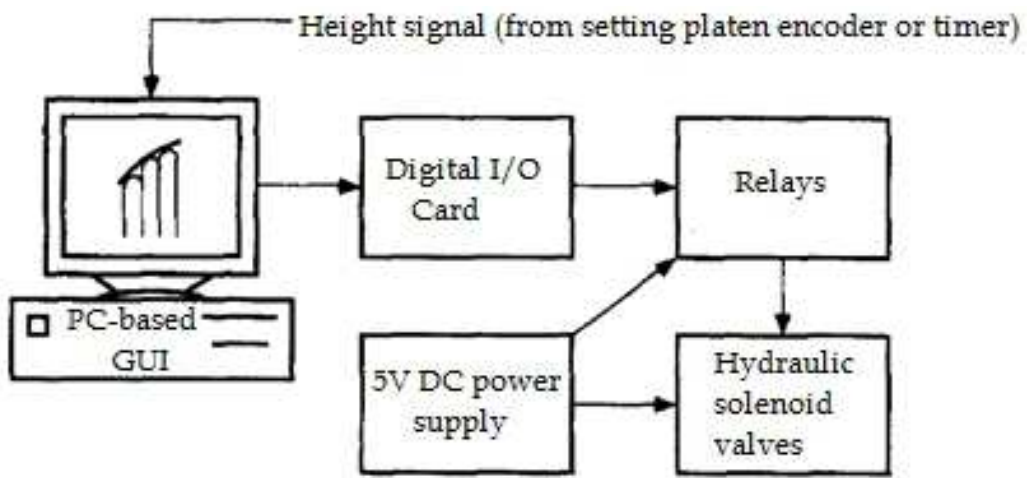

Fig. 14. Test Schematic of Die Control System (Walczyk \& Hardt, 1998). 


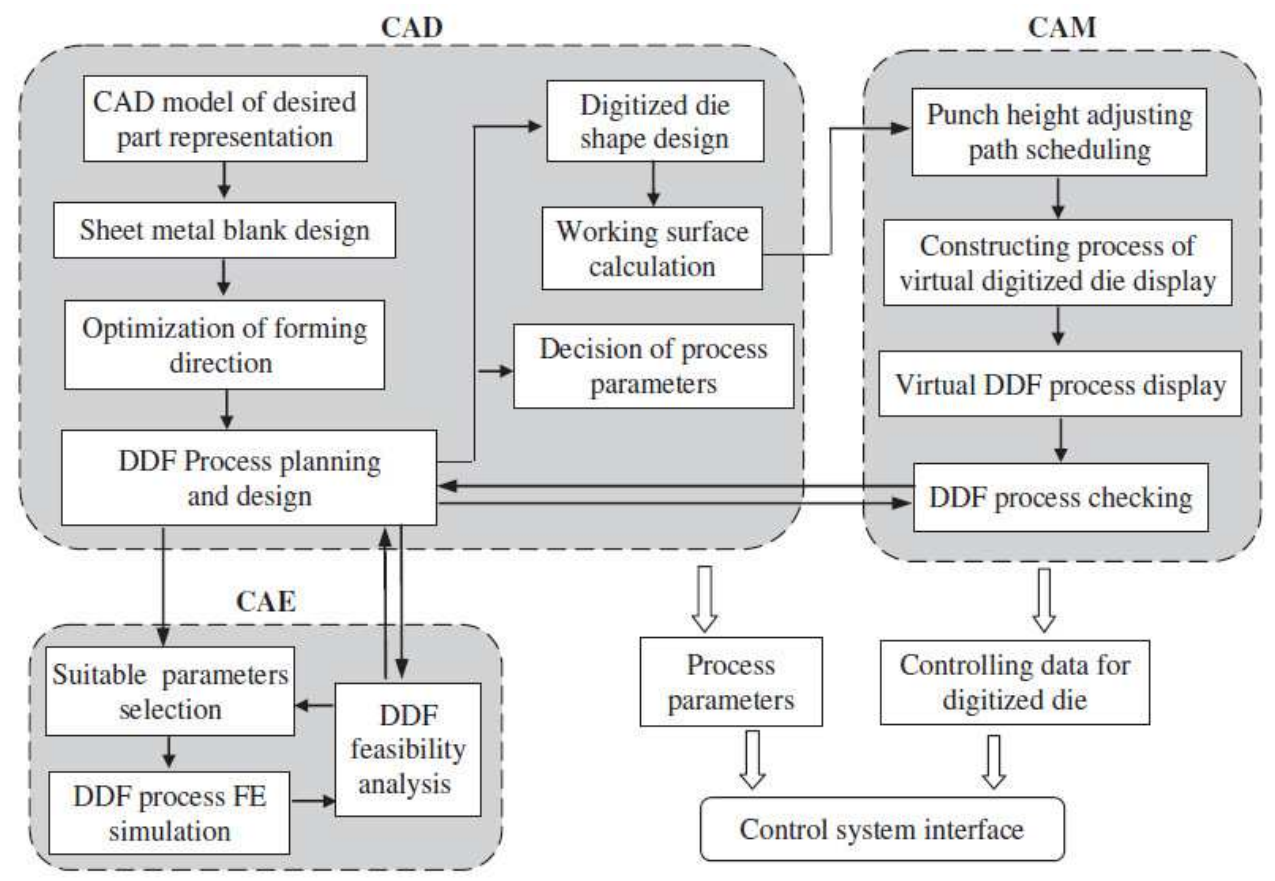

Fig. 15. CAD/CAE/CAM software control for DFF (Li, 2007).

\subsection{Shape memory alloy actuators}

The uses of SMA as actuators nowadays are not only medical devices; there are also novelty actuators such as (Humbeeck, 1999):

- Fashion and gadgets: single products were created from cell phone antennas, eye glasses frames and in the clothing industries frames for brassieres and wedding dresses pericoats (Duering, 1990).

- Couples: Heat-recoverable couplings of an F-14 hydraulic turbine were the first large scale produce actuator (Duering, 1990).

- Micro-actuators: The central Research Institute of Electric Power Industry in Japan built a piston-driver from a $2 \mathrm{~mm}$ diameter wire based on 26 bars, having a life cycle over 500 000 cycles minimum.

- Adaptive materials: A vibrator frequency control of a polymer beam has been used to increase the natural frequency of the composite beam.

- Other applications: Wear cavitations defects where hydraulic machinery are used like water turbines, ship propellers and sluice channels (Jardine et al, 1994).

\subsection{Development of reconfigurable die based on NiTi actuator}

An active multi point forming tool, based on NiTi wires as main actuators is developed. The devices is known as 'reconfigurable die'. 


\subsubsection{Hypothesis}

The main issue on the development of multi point surfaces is that a high density matrix of pins is required, as smaller are the pins smoother is the surface that can be formed. This issue can be solved by using a small actuator that allows formation of a dense pins matrix. SME of NiTi can be applied to achieve the movement of a mechanism that controlls the movement of each pin

\subsubsection{Methodology}

Development of a reconfigurable die follows the concept of DDF. Hence, it is required to design a mechanism, a controller and a graphical user interface (GUI), the full system is shown in Fig. 16.

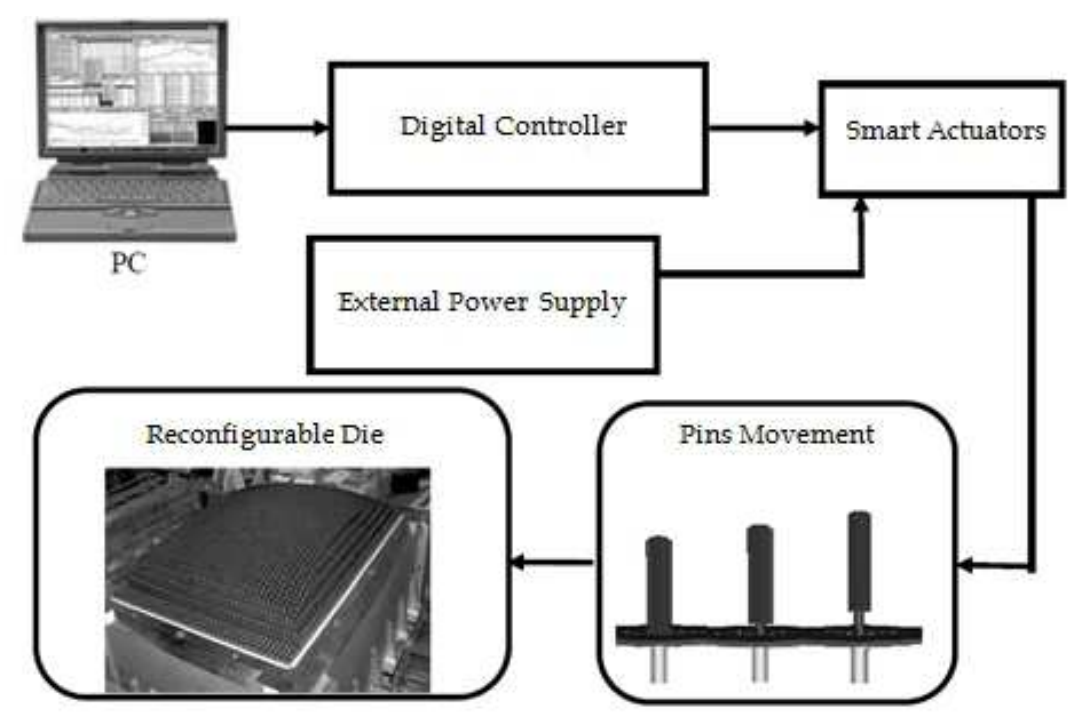

Fig. 16. Overall Process Variables.

\subsubsection{Mechanism design}

A design of a reconfigurable die proposed has been reviewed in order to identify its components and characterize them, sucha as the length of the shafts, springs parameters and SMA properties (length, diameter, electric current).

\subsubsection{Functional prototype description}

Fig 18 shows the mechanism that controls the vertical movement of each square pin. Each pin has a SMA wire subjected to a spring that deforms it, thus, NiTi has a martensitic structure. When a electric pulse activates the electric current the wire will be heated reaching the austenitic structure returning the wire to the non deformed position pushing the springs and the shaft, that causes that the pin rotates and move up; when the pulse is inactive the springs will deforms the SMA again and the cylce is restarted. 


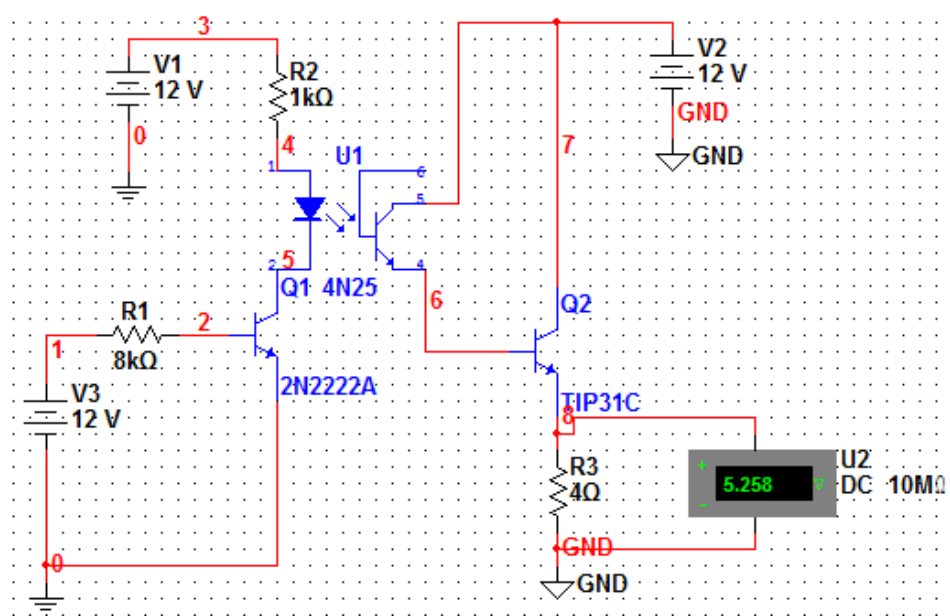

Fig. 17. Electronic design. Power and control circuits, R3 represents NiTi wire.

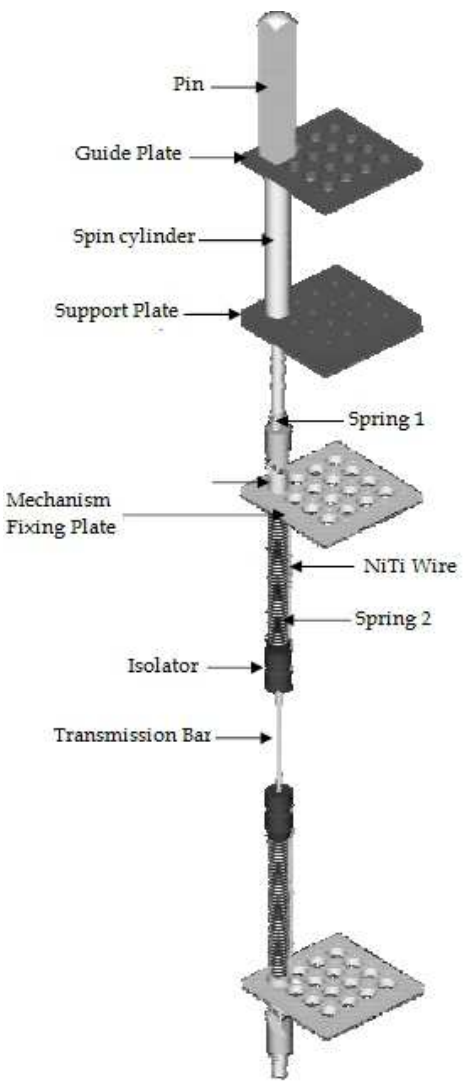

Fig. 18. General Design of the reconfigurable die. 


\subsubsection{Circuitry}

The design consist in a basic control and power electronic circuitry which supplies the current needed to the SMA. Circuit is illustrated in Fig. 17.

\subsubsection{Software}

It was programmed with Labview by National Instrument and consists of three set of parts. The first one is the image codification from a solid figure to a virtual $3 \mathrm{D}$ figure. The second part is the pin head elements array and virtual configuration in the software; finally the last part is the digital output of electric pulses needed per pin head to change its height.

Image codification is performed by pictures taken from the object of interest, in order to make a virtual solid image in a 40 by 40 matrix. The number of views of the object depends of the geometry, a maximum of three pictures can be uploaded (sideway, front, and top views) in order to arrange the pins matrix.

The file from the generated matrix is then placed in the next file, resulting of a specific height for each element; this is then saved in a file as an array in order to visualize the pin design and making a blank. Each element has a resolution of a 28.5 pixel per pin. Fig 19 shows the Human Machine Interface (HMI) software and Fig. 20 shows the matrix of the pins height loaded on the software.

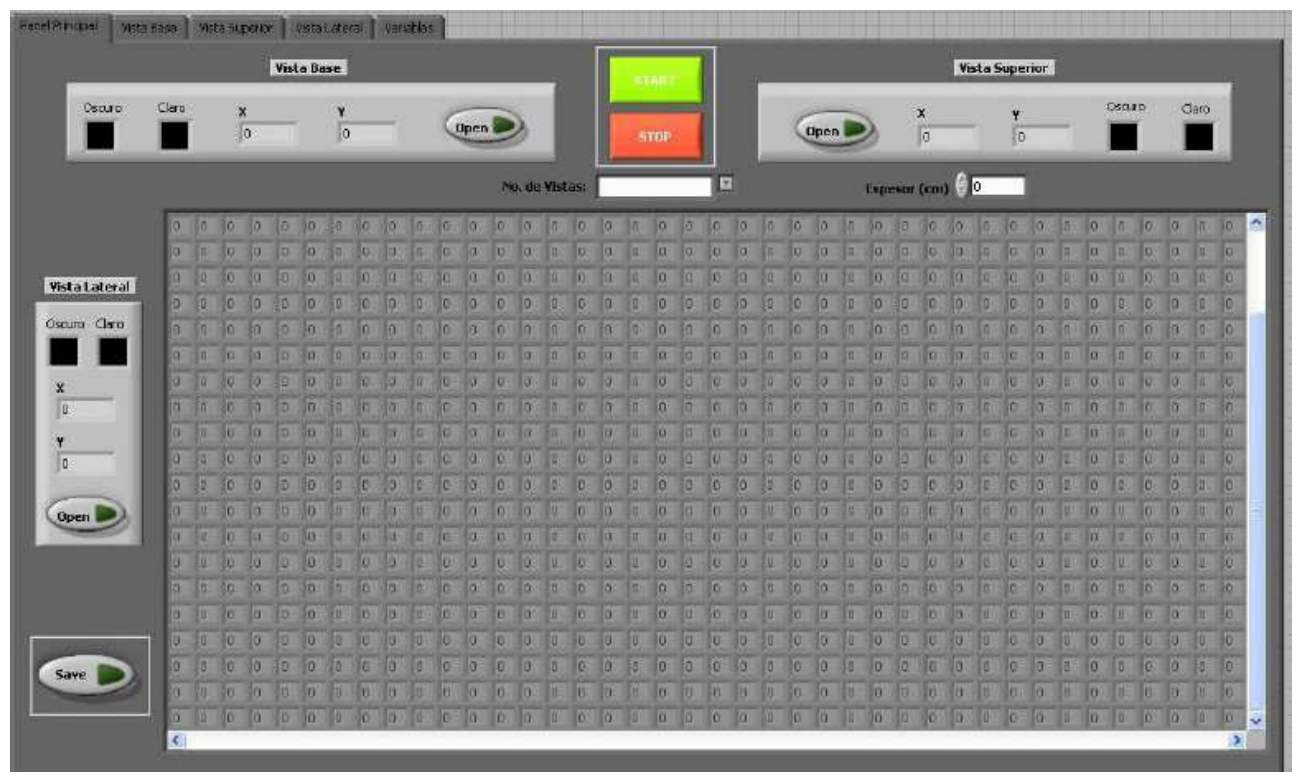

Fig. 19. Software HMI. 


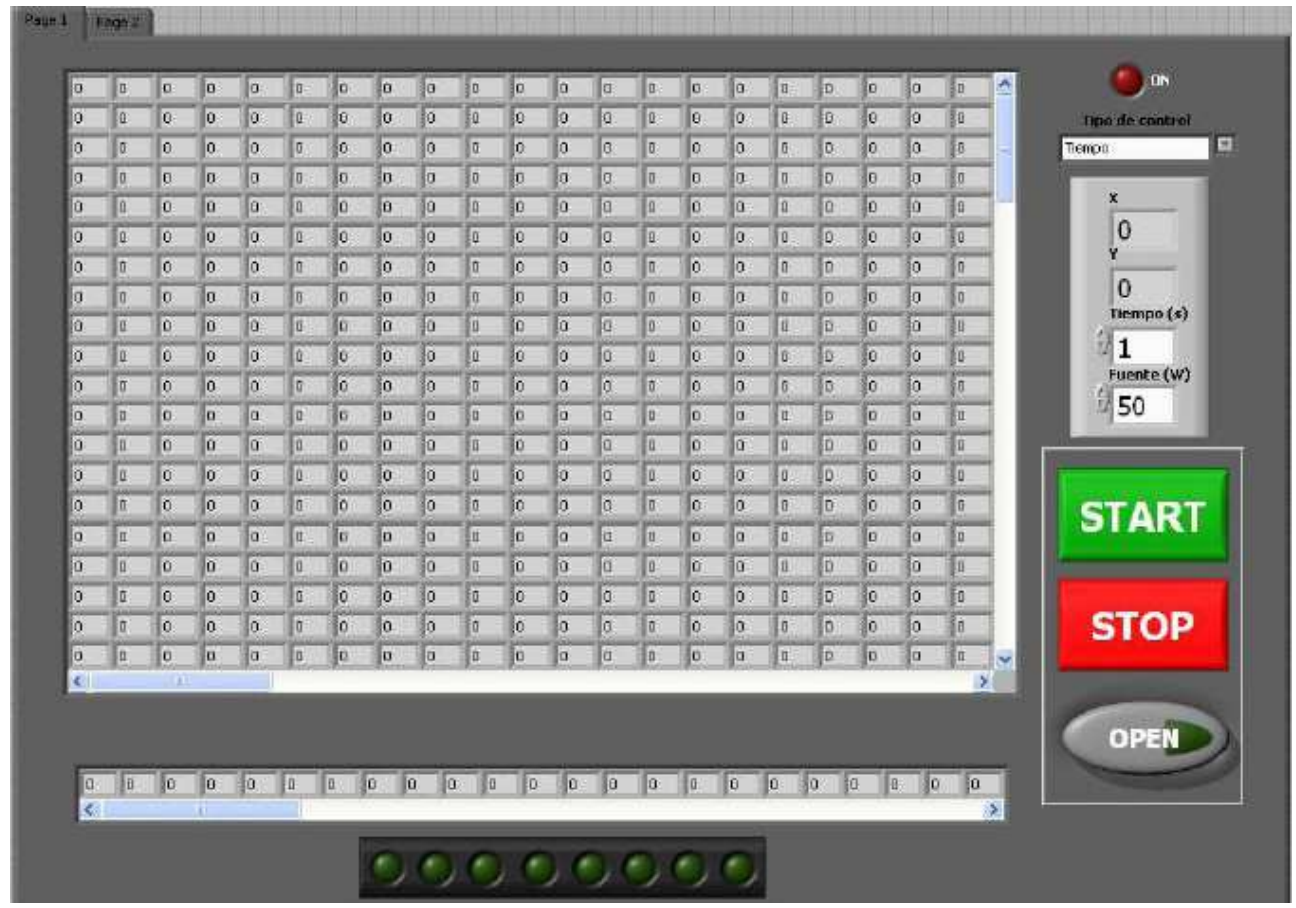

Fig. 20. Matrix pin height.

\subsubsection{Control}

Digital pulses: A digital pulse, as shown in Fig. 21, consists in a square wave of direct current output, on which the duty cycle is fixed, resulting a $50 \%$ high and $50 \%$ low. In this case the "high time" the actuator will be activated with current and the "low time" the signal will be deactivated in order to cool down the actuator.

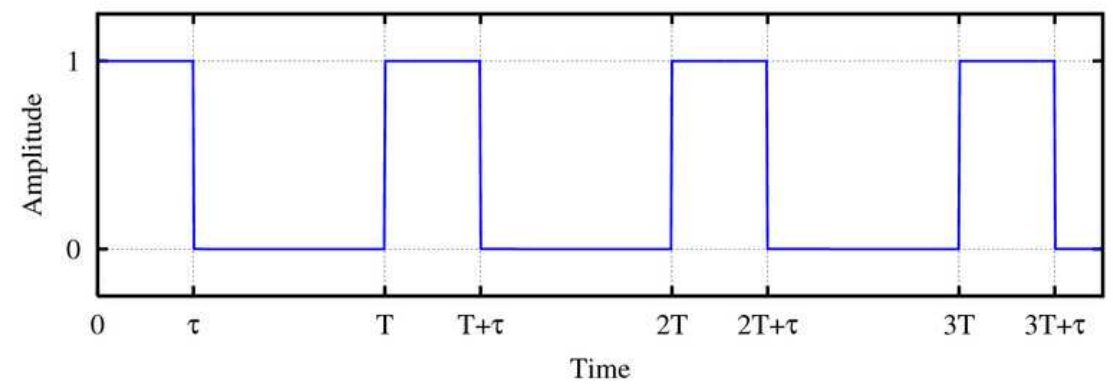

Fig. 21. Digital pulse.

The Duty Cycle (DC) represents the pulse duration divided by the pulse period, where $\tau$ is the duration that the function is actve hight (normally when the voltage is greater then zero) and $\mathrm{T}$ is the period of the function. 
Pulse-width Modulation (PWM): is one of the most efficient ways to provide electrical power between the ranges fully on and fully off. It is a great electric tool to supply voltage/current in ht power electronics field to devices such as electric stoves, robot sensors, dimmers. The main characteristics are the variation and switching between the high and low levels in high frequencies ranges.

PWM, as shown in Fig. 22, uses a rectangular pulse wave whose pulse width is modulated resulting in the variation of the average value of the waveform. The wave has a changing duty cycle, making many pulses in a period of desired time.

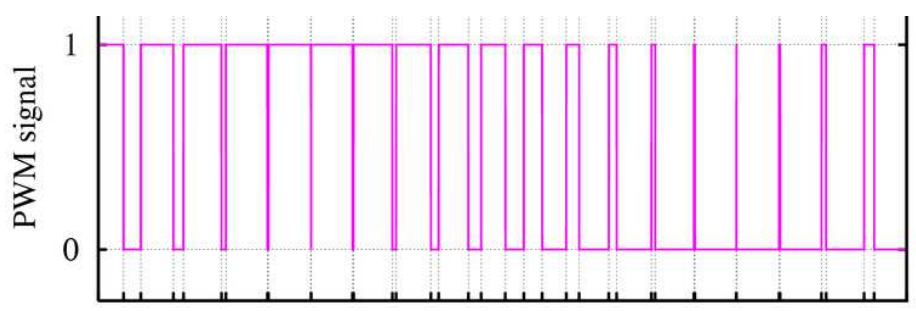

Time

Fig. 22. PWM signal.

In order to select the most appropriate output design in the system, a Design of Experiments (DOE) it is implemented, it is shown in Table 4.

DOE

\begin{tabular}{|l|c|c|}
\hline \multicolumn{1}{|c|}{ Factor } & High level & Low level \\
\hline Time of pulse & 4 second & 2 second \\
\hline Wave output & Single Pulse & PWM Pulse \\
\hline Power Type & 5.5 Watts & 13 Watts \\
\hline
\end{tabular}

Table 4. DOE for evaluating the electric pulse output of each pulse.

For testing purposes, the PWM has a high frequency of $10 \mathrm{KHz}$, for the single pulse the duty cycle is a $50 \%$. The time of pulse is the total amount of the pulse.

According to the tests, the results indicates that the factor of type of power and time of pulse have an impact and the best results on the actuator to return to the original position and having a bigger recovery force is the single pulse in a lower time with a medium range power supply.

The control design to activate the movement of the elements, there are two different methods that can be considered, as described in Table 5 .

\begin{tabular}{|l|l|l|}
\hline \multicolumn{1}{|c|}{ Method } & \multicolumn{1}{|c|}{ Definition } & \multicolumn{1}{c|}{ Elapsed time } \\
\hline Serial & $\begin{array}{l}\text { Elevates the height of each pin from each } \\
\text { row is elevated one at a time. }\end{array}$ & Longer \\
\hline Parallel & $\begin{array}{l}\text { Elevates the height of all pins from each row } \\
\text { is elevated. }\end{array}$ & Shorter \\
\hline
\end{tabular}

Table 5. Pin actuation scheme 
The difference in time setting can be calculated simply by adding the quantity of total cycles from all the pins in the matrix and multiplying by the total time per one pulse in seconds.

\subsubsection{Final prototype}

The final alpha prototype is shown in Figs 23 and 24.

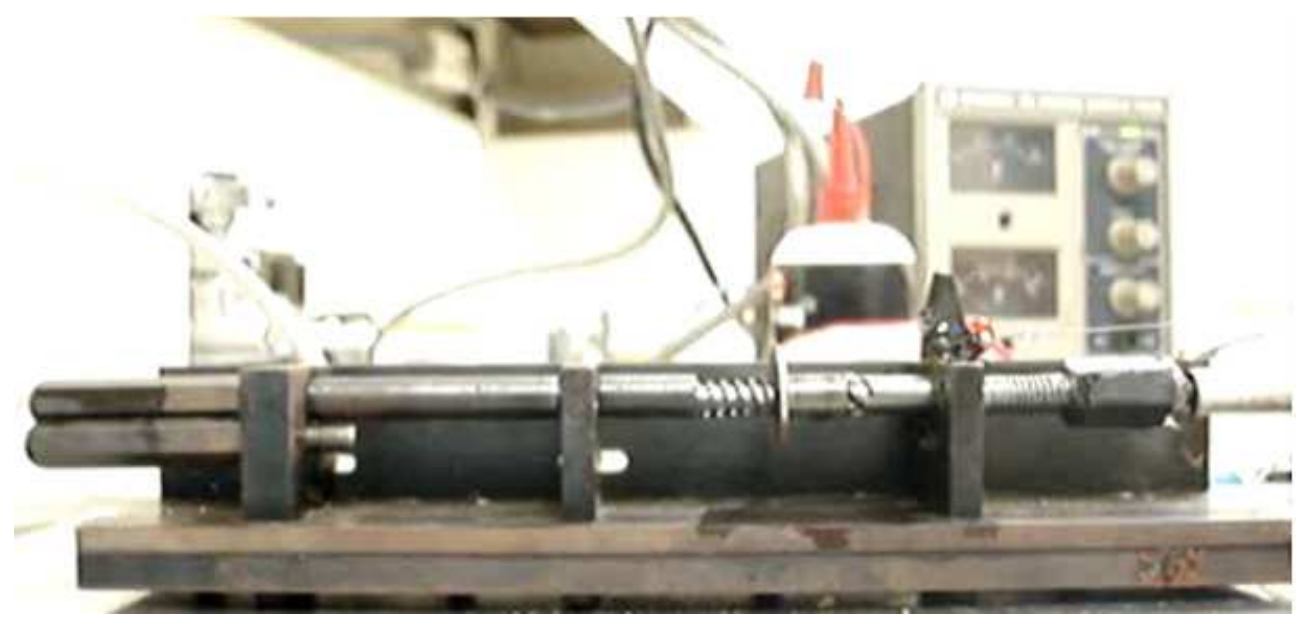

Fig. 23. Machined prototype.

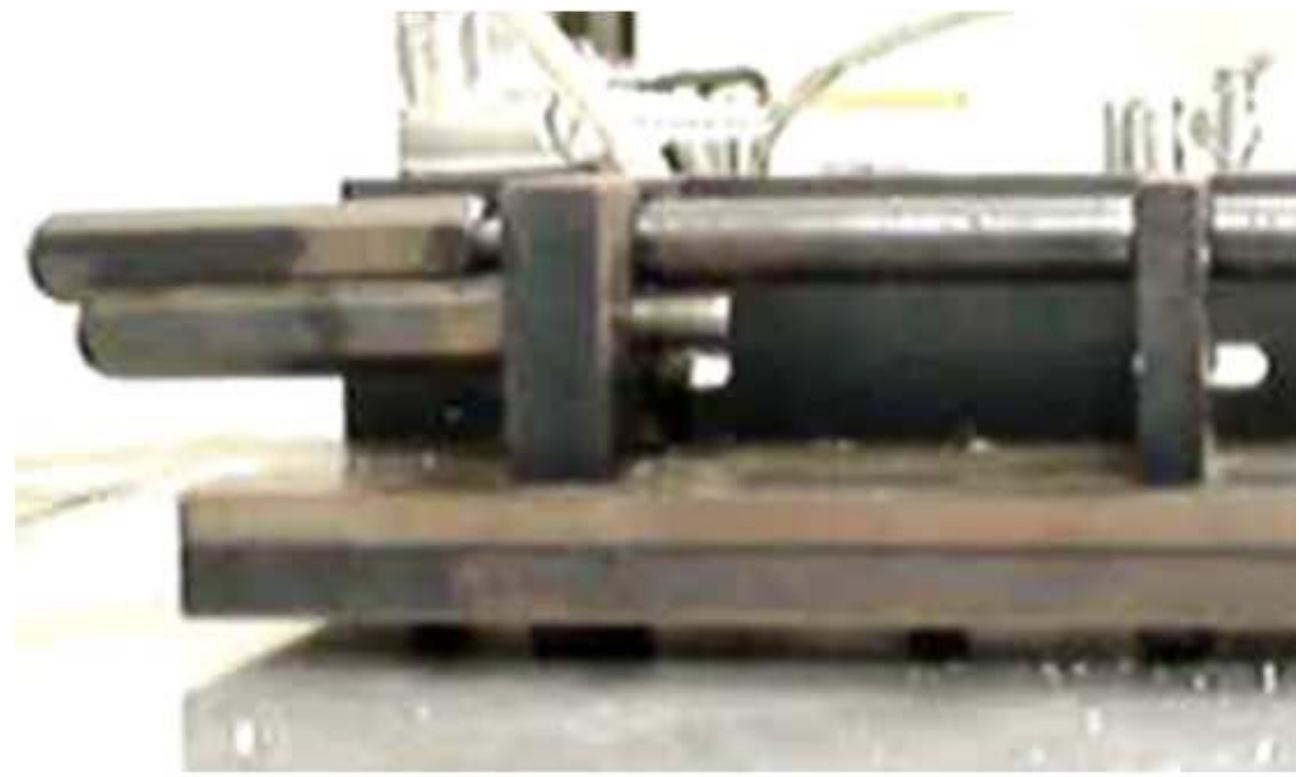

Fig. 24. Pin element changes height. 


\subsubsection{Operation process}

The manufacture process and the use of this tool, allows a technological advantage in the design of a multi-point shape with a reconfigurable die. Its use involves CAD, CAM and CAE technologies as shown in Fig. 25.

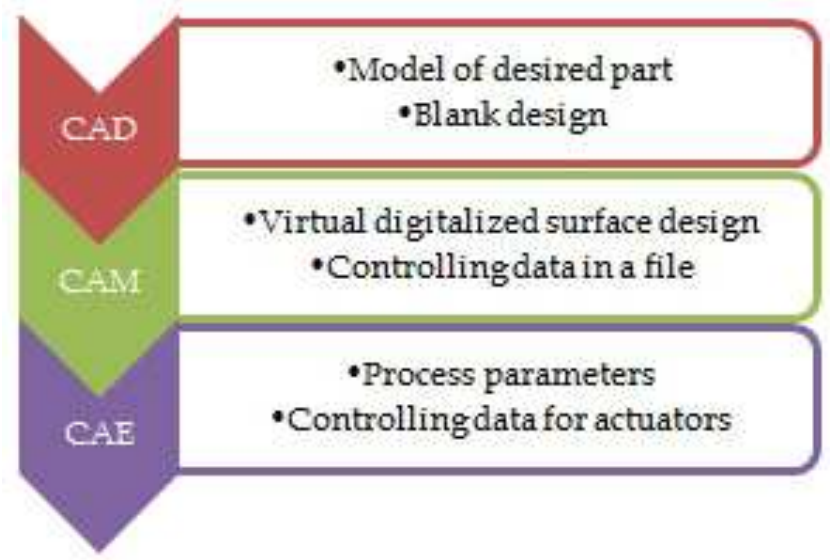

Fig. 25. Technologies used.

Image: the image depends on the views taken by the camera and the position of the object, the files are imported to the matrix arrangement software file to create a virtual object.

Virtual Matrix: when selecting the geometry of the matrix, the columns and rows are selected to visualize the object. The object then will be saved in a matrix file in the hard drive, containing the position of the elements needed from all the matrix, this allow the user to save as many designs and objects without repeating the image step every time.

Physical Matrix: Importing the matrix file, then the software will calculate the number of total cycles per element needed to reach the certain height. In this file the type of control (Parallel or Serial) is defined with the Data Adquisition Card (DAQ) digital outputs.

These proceeses are resumed in Fig. 26.
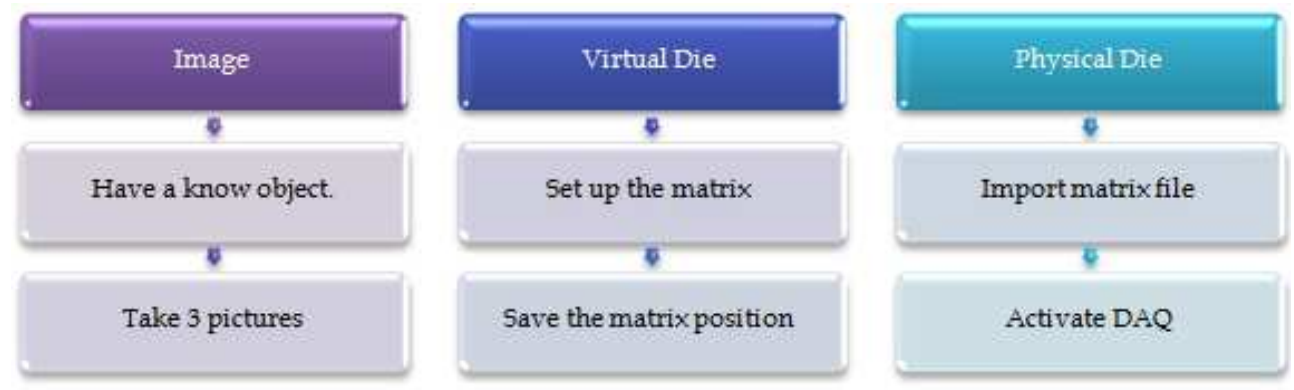

Fig. 26. Processes description. 


\section{Conclusions}

The proposed cconstitutive model for stress on NiTi relates microstructure with thermomechanical behavior of NiTi. A single expression considers the 3 possible existent microstructures and their strain/temperature induced phase transformation.

The size and design of a reconfigurable tool has a strong relationship with size and design of the actuator on which the elements will be positioned in a matrix array.

The use of a reconfigurable actuator such as SMA, makes a more detail design of the pieces and decrements the size and shape of the overall elements, as seen previously in this chapter, making a highly dense pin head per matrix area resulting on a more continuous shape for the discrete shape.

The use of a step by step method such as the one proposed, makes the process an adaptable and enhanced the Vision of Manufacturing Challenges 2020 a reachable goal.

The establishment of the mechanical and electronic parameters of the proposed in order to make a functional prototype, demonstrates that the use of shape memory alloy as actuator can be possible.

The methodology recommended complies the flexibility of a reconfigurable tool according to the Manufacture Vision Challenges 2020, making a modular and adaptable process. (From the object processing image to a virtual matrix array visualizing the final surface created by the matrix arrangement of the pin elements.)

\section{References}

Azadi, B., Rajapakse, R., \& Maijer D. Multi-dimensional constitutive modeling of SMA during unstable pseudoelastic behavior. International journal of solids and structures, Vol. 44, No, 20, (2007), pp. 6473-6490, ISSN 0020-7683

Chang, S., \& Wu S. Internal friction of R-phase and B19' martensite in equiatomic TiNi shape memory alloy under isothermal conditions. Journal of Alloys and Compounds, Vol. 437, (2007), pp. 120-126, ISSN 0925-8388

Cortes, J., Tsuta, T., Mitani, Y., \& Osakada, K. Flow stress and phase transformation analyses in the austenitic stainless steels under cold working. Japan Society of Mechanical Engineers International Journal, Vol. I35 No. 2, (1992), pp. 201-209.

De Castro J A., Melcher K., Noebe R., \& Gaydosh D. Development of a numerical model for high-temperature shape memory alloys. Smart Materials and Structures. Vol 16. (2007). pp. 2080-2090.

Duering, TW., Melton, K., \& Stockel D.Engineering Aspects of Shape Memory Alloys. Materials and Manufacturing Processes, (1990).

Guzman, J., Cortes, J., Fuentes, A., Kobayashi, T., \& Hoshina, Y. Modeling the displacement in three-layer electroactive polymers using different counter-ions by a phase transformation approach. Journal of Applied Polymer Science, Vol. 112, No.6,(June 2009), pp. 3284-3293. ISSN 1097-4628

Humbeeck, J. Non-medical applications of shape memory alloys. Materials Science and Engineering, (1999). 
Kallio, M., Lahtinen, R., \& Koskinen, J. (2003). Smart materials. Smart materials and structures. VTT Research Program 2000-2002 Seminar. Retrieved from <http://www.vtt.fi/inf/pdf/symposiums/2003/S225.pdf>

Lahoz, R., \& Puértolas, J. Training and two-way shape memory in NiTi alloys: influence on thermal parameters. Journal of Alloys and Compounds, Vol. 381, (2004), pp. 130-136, ISSN 0925-8388

Li, M. Multi-point forming technology for sheet metal. Journal of Materials Processing Technology, (2002), pp. 333-338.

Li, M. Manufacturing of sheet metal parts based on digitized-die.Robotics and ComputerIntegrated Manufacturing, (2007), pp. 107-115.

Li, M., Cai, Z., Sui, Z., \& Li, X. Principle and applications of multi-point matched-die forming for sheet metal. Proceedings of the Institution of Mechanical Engineers, Part B: Journal of Engineering Manufacture, Vol. 222, (May, 2008), pp. 581-589.

Malukhin K \& Ehmann K. Material Characterization of NiTi Based Memory Alloys Fabricated by the Laser Direct Metal Deposition Process. Journal of Manufacturing Science and Engineering. Vol. 128, (2006 ), pp. 691-696, ISSN 1087-1357

McNaney J., Imbeni V., Jung Y., Papadopoulos P., \& Ritchie R. An experimental study of the superelastic effect in a shape-memory Nitinol alloy under biaxial loading. Mechanics of Materials, Vol. 35 (2003), pp. 969-986, ISSN 0167-6636

Mehrabi, M., Ulsoy, G., \& Koren Y. Reconfigurable Manufacturing Systems: Key to Future Manufacturing. Journal of Intelligent Manufacturing, Vol.11, No.4, (August 2000), pp. 403-419, ISSN 0956-5515

Nakajima, N. A Newly Develop Technique to Fabricate Complicated Dies and Electrodes with Wires. Japan Society of Mechanical Engineers International Journal, (1986).

National Research Council. Visionary Manufacturing Challenges For 2020, (1998). National Academies Press. Retrieved from <www.nap.edu/readingroom/books/visionary>

Nemat-Nasser S., \& Guo W. Superelastic and cyclic response of NiTi SMA at various strain rates and temperatures Mechanics of Materials. Vol 38, (2006), pp. 463-474, ISSN 0167-6636

Peng, L. Transition surface design for blank holder in multi-point forming. International Journal of Machine Tools \& Manufacture, (2006), pp.1336-1342.

Rao, P. A flexible surface tooling for sheet-forming processes: conceptual studies and numerical simulation. Journal of Materials Processing Technology, (2002).

Ryhänen J. Biocompatibility Evaluation Of Nickel-Titanium Shape Memory Metal Alloy. University of Oulu. (1999). Retrieved from <http://herkules.oulu.fi/isbn9514252217/html>

Schwarz, R. Design and Test of a Reconfigurable Forming Die. Journal of Manufacturing Processes, (2002), pp. 77-85.

Shaw, J. A thermomechanical model for a 1-D shape memory alloy wire with propagating instabilities. International Journal of Solids and Structures, Vol. 39, (2002), pp. 1275-1305, ISSN 0020-7683

Srinivasan, A., \& McFarland D. Smart Structures Analysis and Design (2001), Cambridge University Press. ISBN 0-521-65026-7, Cambridge UK

Varela, M., Cortes, J., \& Chen Y. Constitutive Model for Glassy - Active Phase Transformation on Shape Memory Polymers considering Small Deformations. 
Journal of Materials Science and Engineering, Vol. 4, No. 5 (May 2010), pp 14-22, ISSN 1934-8959

Vision 2020 Chemical Industry of The Future. Roadmap for Process Equipment Materials Technology, (2003). Retrieved from

<www.chemicalvision2020.org/techroadmaps.html>

Walczyk, D., \& Hardt, D. Design and Analysis of Reconfigurable Discrete Dies for Sheet Metal Forming. Journal of Manufacturing Systems, Vol.17, No.6, (1998)

Walczyk, D. A Comparison of Pin Actuation Schemes for Large-Scale Discrete Dies. Journal of Manufacturing Processes, (2000), pp. 247-257.

Zhang, Q. Numerical Simulation of deformation in multi-point sandwich forming. Machine Tools E Manufacturing. (2006): pp. 699-707.

Zhong-Yi, C. Multi-point forming of three-dimensional sheet metal and the control of the forming process. International Journal of Pressure Vessels and Piping. (2002): pp. 289296. 


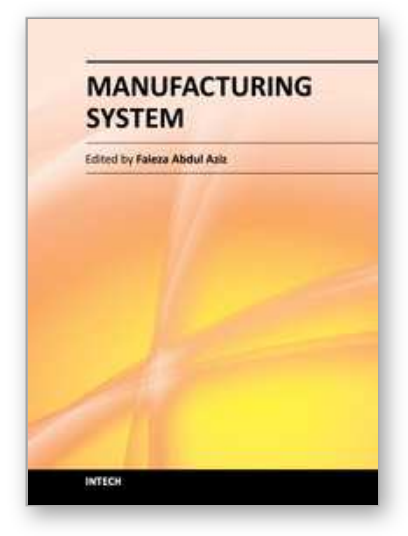

\author{
Manufacturing System \\ Edited by Dr. Faieza Abdul Aziz
}

ISBN 978-953-51-0530-5

Hard cover, 448 pages

Publisher InTech

Published online 16, May, 2012

Published in print edition May, 2012

This book attempts to bring together selected recent advances, tools, application and new ideas in manufacturing systems. Manufacturing system comprise of equipment, products, people, information, control and support functions for the competitive development to satisfy market needs. It provides a comprehensive collection of papers on the latest fundamental and applied industrial research. The book will be of great interest to those involved in manufacturing engineering, systems and management and those involved in manufacturing research.

\title{
How to reference
}

In order to correctly reference this scholarly work, feel free to copy and paste the following:

Jorge Cortes, Ignacio Varela-Jimenez and Miguel Bueno-Vives (2012). Reconfigurable Tooling by Using a Reconfigurable Material, Manufacturing System, Dr. Faieza Abdul Aziz (Ed.), ISBN: 978-953-51-0530-5, InTech, Available from: http://www.intechopen.com/books/manufacturing-system/reconfigurable-tooling-byusing-a-reconfigurable-material

\section{INTECH}

open science / open minds

\section{InTech Europe}

University Campus STeP Ri

Slavka Krautzeka 83/A

51000 Rijeka, Croatia

Phone: +385 (51) 770447

Fax: +385 (51) 686166

www.intechopen.com

\section{InTech China}

Unit 405, Office Block, Hotel Equatorial Shanghai

No.65, Yan An Road (West), Shanghai, 200040, China

中国上海市延安西路65号上海国际贵都大饭店办公楼405单元

Phone: +86-21-62489820

Fax: +86-21-62489821 
(C) 2012 The Author(s). Licensee IntechOpen. This is an open access article distributed under the terms of the Creative Commons Attribution 3.0 License, which permits unrestricted use, distribution, and reproduction in any medium, provided the original work is properly cited. 